\title{
Relationship between feed characteristics and histomorphometry of small intestines of growing pigs
}

\author{
A. G. Bakare ${ }^{1,2 \#} \&$ M.Chimonyo ${ }^{1}$ \\ ${ }^{1}$ Animal and Poultry Science, School of Agricultural, Earth and Environmental Sciences, \\ University of KwaZulu-Natal, Pietermaritzburg, South Africa, 3209 \\ ${ }^{2}$ Department of Agriculture and Animal Health, University of South Africa, Private Bag X6, Florida, 1710, South Africa
}

(Received 16 August 2016; Accepted 29 November 2016; First published online 7 December 2016)

Copyright resides with the authors in terms of the Creative Commons Attribution 4.0 South African License.
See: http://creativecommons.org/licenses/by/4.0/za
Condition of use: The user may copy, distribute, transmit and adapt the work, but must recognize the authors and the South African
Journal of Animal Science.

\begin{abstract}
The use of agricultural by-products has become the central focus in reducing feed costs in pig production. However, there is a need to determine how the gastrointestinal tract of pigs responds when subjected to fibrous ingredients. The objective of the study was to predict villi height and apparent villi surface area from physicochemical measurements of maize cob-based diets. Eighteen growing male pigs (initial bodyweight $14.3 \pm 1.20 \mathrm{~kg}$ ) were used in the experiment. The pigs were penned individually and subjected to diets containing $0 \mathrm{~g}, 80 \mathrm{~g}, 160 \mathrm{~g}, 240 \mathrm{~g}, 320 \mathrm{~g}$, and $400 \mathrm{~g}$ maize cob meal $/ \mathrm{kg}$ diet. Feed and water were provided ad libitum. Using stepwise regression, bulk density (BD) and neutral detergent fibre (NDF) were the best predictor variables influencing villi height $(\mathrm{VH})$ and apparent villi surface area (AVSA). $\mathrm{VH}$ produced quadratic and linear responses with $\mathrm{BD}$ and NDF, respectively. The equations are $\mathrm{VH}=$ 211.3(BD) $)^{2}-591.0(\mathrm{BD})+442.4$; and $\mathrm{VH}=0.03(\mathrm{NDF})+22.8$. Conversely, AVSA produced quadratic and linear responses with NDF and BD, respectively. The equations are AVSA $=0.00036(N D F)^{2}-0.012$ (NDF) +7.25 and $\mathrm{AVSA}=-47.12(\mathrm{BD})+45.03$. In conclusion, the BD and NDF of a feed could be used to predict $\mathrm{VH}$ and AVSA of growing pigs fed maize cobs.
\end{abstract}

Keywords: maize cob meal, mucosa lining, physicochemical properties, visceral organs

\# Corresponding author: archiebakare@gmail.com

\section{Introduction}

Use of alternative resources to feed pigs reduces competition for grain with humans. Fibrous feed ingredients for example can be used as a cheap energy source for feeding pigs (Bakare et al., 2016). These feed ingredients have been reported to interact with the microflora and the mucosa of all sites of the gastrointestinal tract (GIT), which are major components of optimal gut health (Montagne et al., 2003). Optimum gut health describes aspects such as effective digestion and absorption of nutrients, the absence of GIT illness, normal and stable intestinal microbiota, effective immune status, and a state of wellbeing. The GIT, which is the first organ system that is affected directly by fibrous diets, displays acute and long-term adaptations (Ferraris \& Carey, 2000). Such changes occur to the visceral organs and mucosal architecture of the intestines. Mucosal architecture relates to villi height $(\mathrm{VH})$ and crypt depth (CD) and is influenced by feeding level and composition of diets.

There are conflicting reports on the influence of dietary fibre on the mucosal architecture. High fibre inclusion levels were reported to increase VH and CD (Ngoc et al., 2012), and to decrease VH (Agyekum et al., 2012). Some reports have argued that fibre does not influence mucosal architecture (Jin, 1992; Jin et al., 1994). Different fibre sources elicit varied impacts on the mucosa lining. Using physicochemical properties of fibrous diets, therefore, would increase the level of accuracy for predicting the mucosal architecture of the intestines. The relationship between diet characteristics and VH and apparent villi surface area (AVSA) provides a theoretical basis in the formulation of diets for weaner pigs. Feed compounders would formulate diets that allow optimum gut health in pigs from the fibrous feed sources.

Maize cobs were used in this study as a fibrous ingredient and are the remains after the kernels have been removed. About $180 \mathrm{~kg}$ to $200 \mathrm{~kg}$ maize cobs are produced per tonne of grains (Božović et al., 2004). This translates to significant quantities of maize cobs being potentially available as feed for livestock. Villi 
height and AVSA determine absorptive capacity of nutrients for use by the pigs, which consequently determines their overall performance (Naburrs et al., 1993; Vente Spreeuwenberg \& Beynen, 2003). Visceral organs also contribute to the efficiency of converting dietary nutrients in pork products (De Lange et al., 2001). Hence, they were measured in this experiment. The main objective of the study, therefore, was to determine the relationship between feed characteristics (physicochemical properties) and histomorphometry (VH and AVSA) of small intestines of growing pigs.

\section{Materials and methods}

A total of 18 clinically healthy castrated male growing pigs, weighing $14.3 \pm 1.20 \mathrm{~kg}$ were used in the experiment. The pigs were treated in accordance with the University of KwaZulu-Natal Guidelines for the Care and Use of Laboratory Animals (Reference number: 061/12/Animal). All pigs were penned individually in metabolism crates measuring $1.5 \times 1 \mathrm{~m}$ and containing a plastic tube feeder (Big Dutchman Lean Machine $\left.{ }^{\circledR}\right)$ and a low-pressure nipple drinker. The diets and drinking water were provided ad libitum throughout the experimental period. HOBO data loggers (Onset Computer Corporation, Pocasset, Mass., USA) were used to automatically record ambient temperatures and relative humidity during the trial. The average temperature and humidity during the study period were $21^{\circ} \mathrm{C}$ and $42.6 \%$, respectively.

A premium commercial feed (Meadow Feeds Ltd, Pietermaritzburg, South Africa) with a low level of DF was used as the basal feed. The basal diet had these ingredients; yellow maize $(500 \mathrm{~g} / \mathrm{kg})$, soya bean $(158 \mathrm{~g} / \mathrm{kg})$, soybean oil cake $(20.2 \mathrm{~g} / \mathrm{kg})$, wheat bran $(163 \mathrm{~g} / \mathrm{kg})$, sunflower oil cake $(85 \mathrm{~g} / \mathrm{kg})$, molasses syrup $(25 \mathrm{~g} / \mathrm{kg})$, and additives $(48.8 \mathrm{~g} / \mathrm{kg})$. The maize cobs were first ground to pass through a 3-mm screen. Thereafter, the grounds were included at $0 \mathrm{~g}, 80 \mathrm{~g}, 160 \mathrm{~g}, 240 \mathrm{~g}, 320 \mathrm{~g}$ and $400 \mathrm{~g}$ maize cob meal $/ \mathrm{kg}$ diet of pigs. Three pigs were randomly allocated to each treatment diet in the experiment. The number was sufficient for the study to provide data points for determining relationships. It was assumed that the pigs would increase their intake in proportion to the degree of dilution of the basal feed with the maize cob. They were allowed to adapt to the feed for seven days.

All feed samples were oven-dried and ground to pass through a 1-mm sieve before analysis. Ash (method 942.05), dry matter (DM) (method 2001.12), and crude protein (CP) (method 990.03) were determined according to the method of AOAC (2005). Gross energy was determined with a bomb calorimeter (Model C2000 basic IKA Co., Germany). NDF and ADF were analysed with filter bags by a fibre analyser (Ankom 220, Ankom Technology Corp) (Ferreira \& Mertens 2007). NDF and ADF are considered a complete description of fibre in a diet and can be used as nutrients to improve feed intake and efficiency of growth in pigs. Hence, the nutrients were considered for analysis instead of total dietary fibre and non-starch polysaccharides. BD of the feeds was measured according to the water displacement method (Peterson \& Baumgardt, 1971). Water-holding capacity (WHC) was determined by centrifugation (Robertson \& Eastwood, 1981). Three replicates for each sample were analysed. Table 1 shows the chemical and physicochemical properties of diets.

Table 1 Chemical and physicochemical properties of diets

\begin{tabular}{lcccccc}
\hline & \multicolumn{5}{c}{ Inclusion level $(\mathrm{g} / \mathrm{kg})$} \\
\cline { 2 - 7 } & 0 & 80 & 160 & 240 & 320 & 400 \\
\hline DM (g/kg) & 989.3 & 989.3 & 990.4 & 990.5 & 990.2 & 991.1 \\
1 calc DE (kcal/kg) & 3320.0 & 3152.8 & 2890.0 & 2627.3 & 2460.1 & 2221.3 \\
CP (g/kg DM) & 195.7 & 185.7 & 168.1 & 152.8 & 139.4 & 116.4 \\
EE (g/kg DM) & 52.9 & 51.2 & 45.9 & 45.2 & 41.3 & 39.9 \\
Ash (g/kg DM) & 61.1 & 59 & 54.9 & 53.2 & 52.1 & 46.7 \\
NDF(g/kg DM) & 192.3 & 230.6 & 294.4 & 355.3 & 401.3 & 457.4 \\
ADF(g/kg DM) & 88.4 & 111.5 & 147.4 & 181.2 & 218.4 & 250.5 \\
Density (ml/g DM) & 1.45 & 1.52 & 1.47 & 1.42 & 1.25 & 1.22 \\
WHC (g water/g DM) & 3.76 & 3.17 & 3.57 & 4.08 & 4.41 & 4.75
\end{tabular}

DM: dry matter; GE: gross energy; CP: crude protein; EE: ether extract

NDF: neutral detergent fibre; ADF: acid detergent fibre; WHC: water holding capacity

${ }^{1}$ calc DE $=949+(0.789 \times$ GE $)-(43 \times \%$ Ash $)-(41 \times \%$ NDF $)$ (Noblet \& Perez, 1993) 
After four weeks on the experimental diet, pigs were euthanized with intravenous injections using sodium pentobarbitone (Kyron Company, C92/1.9/6). Then the pigs were slit open in the abdomen and all the intestines and organs (liver and pancreas) in the abdominal cavity were removed. The intestines were untwined and lengths of the small and large intestines were recorded. The weights of the liver and pancreas and the empty weights of the small and large intestines and stomachs were also recorded.

The small intestines of each pig were divided into duodenum, jejunum, and ileum segments. From each intestinal segment, $10 \mathrm{~cm}$ pieces were cut and fixed immediately in $10 \%$ neutral formalin prior to preparation and analysis. The intestinal samples were sectioned and stained with haematoxylin-eosin stain. The sections were observed at $100 \times$ magnification using a light microscope equipped with an ocular micrometre. The VH, CD, villus to crypt ratio, villus apical width and AVSA were recorded. Between eight and 11 randomly chosen and well-oriented villi were selected for measurements. VH was measured from the tip to the base of the villus, and $C D$ was measured from the tip of the crypt to the point where it meets the muscularis mucosa (Velayudhan et al., 2008).

Apparent villus surface area was estimated using the formula (lji et al., 2001):

$\operatorname{AVSA}=\frac{(\mathrm{a}+\mathrm{b})}{2} \times \mathrm{c}$

Where:

$a$ is villus apical width; $b$ is villus basal width;and $c$ is villus height

The data collected for visceral organ and mucosal architecture measurements were divided by the metabolic bodyweight to give relative measurements. This would take account of differences in mean weight between treatment diets (Bailey et al., 2004). Metabolic body weight of each animal was calculated using the formula:

Metabolic body weight $(\mathrm{MBW})=\mathrm{BW}^{0.75}$

Where BW is bodyweight of the pig

Effects of feeding fibrous diets on visceral organs size and length, and mucosal architecture measurements were analysed using the general linear models procedure (SAS, 2008). These models were used:

For visceral organ measurements:

$Y_{i j}=\mu+T R T_{i}+e_{i j}$

where:

$\mathrm{Y}_{\mathrm{ij}}=$ response variable (visceral organ measurements)

$\mu=$ the overall mean response common to all observations

$\mathrm{TRT}_{\mathrm{i}}=$ the effect of the fibre inclusion level

$\mathrm{e}_{\mathrm{ij}}=$ the residual error

For mucosal architecture measurements:

$Y_{i j k}=\mu+T R T_{i}+\operatorname{Seg}(T R T)_{i j}+e_{i j k}$

where:

$Y_{\mathrm{ijk}}=$ response variable (AVSA, CD, VH and $\mathrm{VH}: \mathrm{CD}$ ratio)

$\mu=$ is the overall mean response common to all observations

$\mathrm{TRT}_{\mathrm{i}}=$ the effect of the fibre inclusion level

$\operatorname{Seg}(T R T)_{i j}=$ intestinal segment nested in treatment

$\mathrm{e}_{\mathrm{ijk}}=$ the residual error

Mean separation was done with the PDIFF procedure of SAS (2008) for factors that were significant ( $P$ $<0.05)$. Stepwise regression was used to identify the feed characteristic (DM, GE, CP, BD, EE, NDF, ADF and WHC), which best influenced intestinal VH and AVSA. Thereafter, the quadratic response surface model was used to determine the relationships between feed characteristics selected from stepwise regression and VH and AVSA of the small intestines. Pearson's correlation coefficients between VH and AVSA were also determined. 


\section{Results}

All pigs were clinically healthy at the beginning of the experiment and at the end. Pigs that received diets high in fibre content had low average daily weight gains (ADG) compared to those receiving low fibre diets $(P<0.05)$ (Figure 1).

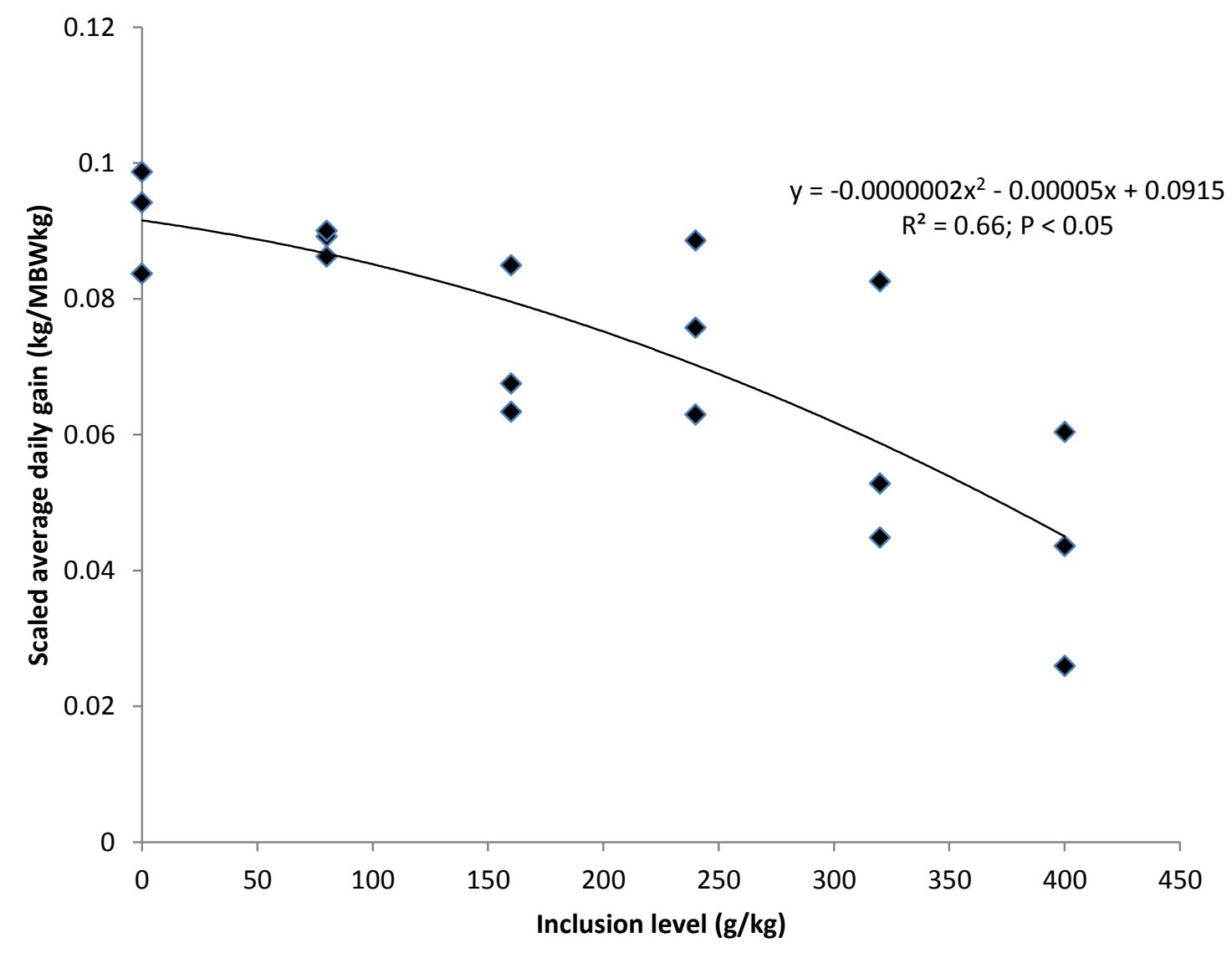

Figure 1 Relationship between scaled average daily gain and inclusion level of maize cob meal

Table 2 shows the means and relationships of organ weights and lengths of intestines of pigs fed diets with varying inclusion levels of maize cob meal. Weights of the livers of pig decreased with inclusion level of maize cob meal $(P<0.05)$. Conversely, pancreas and stomach weights increased with inclusion level of maize cob meal. Weights of the small and large intestines of pigs fed diets with varying inclusion levels of maize cob meal were not different $(P>0.05)$. Lengths of large intestines increased with inclusion level of maize cob meal. Means and relationships of the histological measurements of the mucosa of the intestines of pigs fed diets varying inclusion levels of maize cob meal are shown in Table 3 . Villi height increased with inclusion level of maize cob meal in the duodenum, jejunum and ileum segments of the small intestines $(P$ $<0.05)$. The same trend was also observed for AVSA, which increased with inclusion level of maize cob meal for duodenum and ileum $(P<0.05)$. CD was observed to increase with inclusion level of maize cob meal in all the segments of the small intestines $(P<0.05)$. There were no differences in villi height to crypt depth ratio (VCR) of pigs fed incremental levels of fibre in the jejunum and ileum. VCR decreased with inclusion level of maize cob meal in the duodenum segment of the small intestine $(P<0.05)$. 
Table 2 Visceral organ weights and lengths of growing pigs fed diets with incremental levels of fibre

\begin{tabular}{|c|c|c|c|c|c|c|c|c|c|c|c|}
\hline \multirow[b]{2}{*}{ Organs } & \multicolumn{6}{|c|}{ Inclusion level (g/kg) } & \multirow[b]{2}{*}{ SE } & \multicolumn{2}{|l|}{ Linear } & \multicolumn{2}{|l|}{ Quadratic } \\
\hline & 0 & 80 & 160 & 240 & 320 & 400 & & $\begin{array}{c}\text { Regression } \\
\text { coefficient }\end{array}$ & SE & Regression coefficient & SE \\
\hline \multicolumn{12}{|c|}{ Weights, g/ MBW kg } \\
\hline Liver & 96.05 & 94.76 & 84.53 & 81.90 & 78.46 & 72.97 & 6.592 & $-0.66^{*}$ & 0.638 & NS & - \\
\hline Pancreas & 5.02 & 5.74 & 5.32 & 6.95 & 7.30 & 6.94 & 0.404 & $0.08^{*}$ & 0.047 & NS & - \\
\hline Stomach & 18.80 & 19.37 & 19.78 & 21.24 & 24.18 & 24.15 & 1.708 & 0.07 * & 0.168 & NS & - \\
\hline Small intestine & 102.21 & 84.88 & 95.65 & 86.83 & 95.70 & 100.48 & 5.403 & NS & - & NS & - \\
\hline Large intestine & 52.33 & 49.26 & 56.94 & 49.70 & 48.62 & 67.26 & 6.390 & NS & - & NS & - \\
\hline \multicolumn{12}{|c|}{ Lengths, cm/ MBW kg } \\
\hline Small intestine & 126.14 & 105.10 & 107.49 & 103.23 & 128.15 & 137.31 & 8.117 & -2.26 * & 0.838 & 0.07 * & 0.020 \\
\hline Large intestine & 22.63 & 25.30 & 28.05 & 25.08 & 26.45 & 30.27 & 2.101 & 0.14 * & 0.124 & NS & - \\
\hline
\end{tabular}

MBW: metabolic body weight

NS: not significant $(P>0.05) ;{ }^{*} P<0.05$

SE: standard error 


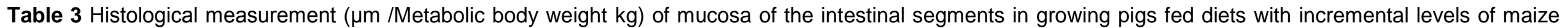
cobs

\begin{tabular}{|c|c|c|c|c|c|c|c|c|c|c|}
\hline \multirow{3}{*}{ Item } & \multirow{2}{*}{\multicolumn{6}{|c|}{ Inclusion level (g/kg) }} & \multicolumn{4}{|c|}{$P$-value } \\
\hline & & & & & & & \multicolumn{2}{|l|}{ Linear } & \multicolumn{2}{|l|}{ Quadratic } \\
\hline & 0 & 80 & 160 & 240 & 320 & 400 & Reg. coeff & SE & Reg. coeffi & SE \\
\hline \multicolumn{11}{|c|}{ Duodenum } \\
\hline $\mathrm{VH}$ & $25.4 \pm 1.68$ & $32.6 \pm 1.63$ & $33.6 \pm 1.40$ & $28.3 \pm 1.73$ & $29.5 \pm 1.79$ & $37.0 \pm 1.54$ & $0.18^{*}$ & 0.089 & NS & - \\
\hline$C D$ & $26.0 \pm 2.25$ & $33.4 \pm 2.19$ & $35.8 \pm 1.88$ & $35.0 \pm 2.33$ & $37.8 \pm 2.41$ & $55.9 \pm 2.07$ & $-0.018^{*}$ & 0.012 & NS & - \\
\hline VCR & $0.97 \pm 0.08$ & $0.8 \pm 0.07$ & $1.0 \pm 0.06$ & $0.8 \pm 0.08$ & $0.8 \pm 0.07$ & $0.7 \pm 0.068$ & $-0.0088^{*}$ & 0.0081 & NS & - \\
\hline AVSA & $5.9 \pm 0.40$ & $6.6 \pm 0.39$ & $8.0 \pm 0.33$ & $6.7 \pm 0.41$ & $7.3 \pm 0.43$ & $9.2 \pm 0.36$ & $0.018^{*}$ & 0.0460 & NS & - \\
\hline \multicolumn{11}{|c|}{ Jejunum } \\
\hline $\mathrm{VH}$ & $24.3 \pm 2.27$ & $30.0 \pm 1.80$ & $33.0 \pm 2.10$ & $32.2 \pm 1.51$ & $29.6 \pm 1.85$ & $38.5 \pm 1.71$ & $0.22^{*}$ & 0.216 & NS & - \\
\hline CD & $30.6 \pm 1.99$ & $28.9 \pm 1.58$ & $32.9 \pm 1.84$ & $32.9 \pm 1.32$ & $33.9 \pm 1.62$ & $39.6 \pm 1.50$ & $-0.071^{*}$ & 0.182 & NS & - \\
\hline VCR & $0.80 \pm 0.08$ & $1.0 \pm 0.07$ & $1.1 \pm 0.08$ & $1.0 \pm 0.06$ & $0.9 \pm 0.07$ & $1.0 \pm 0.06$ & NS & - & NS & - \\
\hline AVSA & $6.5 \pm 0.50$ & $5.7 \pm 0.40$ & $6.7 \pm 0.46$ & $7.5 \pm 0.33$ & $7.6 \pm 0.41$ & $9.5 \pm 0.38$ & $-0.014^{*}$ & 0.0464 & $0.0024^{*}$ & 0.0011 \\
\hline \multicolumn{11}{|l|}{ Ileum } \\
\hline $\mathrm{VH}$ & $26.2 \pm 1.30$ & $27.7 \pm 1.48$ & $35.7 \pm 1.07$ & $26.3 \pm 1.21$ & $34.7 \pm 1.17$ & $38.0 \pm 1.56$ & $-0.16^{\star}$ & 0.069 & NS & - \\
\hline CD & $24.2 \pm 1.90$ & $24.2 \pm 2.16$ & $26.2 \pm 1.57$ & $25.9 \pm 1.77$ & $33.1 \pm 1.71$ & $36.9 \pm 2.28$ & $-0.12^{*}$ & 0.097 & $0.011^{*}$ & 0.0049 \\
\hline VCR & $1.3 \pm 0.10$ & $1.2 \pm 0.11$ & $1.5 \pm 0.08$ & $1.0 \pm 0.09$ & $1.1 \pm 0.09$ & $1.1 \pm 0.12$ & NS & - & NS & - \\
\hline AVSA & $6.2 \pm 0.43$ & $5.3 \pm 0.50$ & $7.4 \pm 0.36$ & $7.4 \pm 0.40$ & $7.5 \pm 0.39$ & $10.7 \pm 0.52$ & $0.015^{\star}$ & 0.005 & NS & - \\
\hline
\end{tabular}

VH: villi height; CD: crypt depth; VCR: VH : CD ratio; AVSA: apparent villi surface area

Reg. coeff: regression coefficient; NS: not significant $(P>0.05) ;{ }^{*} P<0.05$

Table 4 shows correlations of the various histological measurements of mucosa of the small intestines. There was a positive correlation between $\mathrm{VH}$ and AVSA $(P<0.001)$. Moderate negative correlations were observed for VH and VCR, and CD and VCR $(P<0.01)$. AVSA and CD showed a weak negative correlation $(P<0.001)$ 
Table 4 Correlation coefficients for histological measurements

\begin{tabular}{lcccc}
\hline & VCR & CD & AVSA & VH \\
\hline VCR & - & $-0.67^{*}$ & $-0.097 \mathrm{NS}$ & $-0.41^{*}$ \\
CD & & - & $-0.25^{*}$ & $-0.29^{*}$ \\
AVSA & & - & $0.44^{*}$ \\
VH & & & - \\
\hline${ }^{*} P<0.001 ;$ NS: not significant $(P>0.05) ;$ & \\
VCR: VH to CD ratio; CD: crypt depth; AVSA: apparent villi surface area; VH: villi height
\end{tabular}

Using stepwise regression, BD and NDF were the best predictor variables influencing VH and AVSA $(P<0.05)$. VH produced quadratic and linear responses with BD and NDF, respectively $(P<0.05$; Table 5$)$. Conversely, AVSA produced quadratic and linear responses with NDF and BD, respectively $(P<0.05$; Table $5)$.

Table 5 Relationship between physicochemical properties and, villi height and apparent villi surface area

\begin{tabular}{|c|c|c|c|c|c|}
\hline \multirow[b]{2}{*}{ Item } & \multicolumn{3}{|c|}{ Components of regression equation } & \multicolumn{2}{|c|}{ P-value } \\
\hline & $a x^{2}$ & bx & c & Linear & Quadratic \\
\hline VH & $211.3 \pm 58.49(N D F)^{2}$ & $-591.0 \pm 159.06$ (NDF) & $442.4 \pm 107.42$ & * & * \\
\hline VH & & $0.03 \pm 0.0047(\mathrm{BD})$ & $22.8 \pm 1.59$ & * & NS \\
\hline AVSA & $0.000036 \pm 0.0000148(\mathrm{NDF})^{2}$ & $-0.012 \pm 0.00969$ (NDF) & $7.25 \pm 1.493$ & * & * \\
\hline AVSA & & $-47.12 \pm 39.957(\mathrm{BD})$ & $45.03 \pm 26.985$ & * & NS \\
\hline
\end{tabular}

${ }^{*} \mathrm{P}<0.05 ;$ NS: not significant $(P>0.05)$

a: regression coefficient of $x^{2} ; \mathbf{b}$ : regression coefficient of $x$; $\mathbf{c}$ : intercept

$\mathrm{VH}$ : villi height; NDF: neutral detergent fibre; BD: bulk density

\section{Discussion}

In the current study, three pigs were subjected to each treatment diet. The number was sufficient to answer satisfactorily the scientific questions posed by the study. The bodyweight gains of pigs decreased with inclusion level of maize cob meal. The results are in agreement with previous studies (Le Goff et al., 2002; Ndou et al., 2013), which reported a decrease in ADG in growing pigs fed diets high in fibre levels. The observation that feeding diets with incremental levels of maize cob meal produce variable effects on individual visceral organ mass was expected. The increase in relative weight of the pancreas and stomachs agrees with a previous study (Agyekum et al., 2012). The increase in weight of the pancreas might be attributed to hyper-secretion of pancreatic enzymes to compensate for digestion and absorption inefficiency (Pond et al., 1988). At high inclusion levels of fibre, more enzymes are produced to break down coarsetextured feed compared with lower fibre diets. A decrease in the weight of the liver, on the other hand, was observed in pigs in the current study. When pigs were fed diets containing lucerne, an increase in liver weight was reported (Pond et al., 1988; Jørgensen et al., 1996; Nyachoti et al., 2000). On the contrary, a previous study (Ma et al., 2002) reported decreases in liver weights in growing pigs fed on diets with wheat straw. Such conflicting findings suggest that organ weights are influenced by the source of the insoluble fibre.

The weights of the small and large intestines relative to MBW of pigs were not affected by the fibrous diets. This is consistent with a previous study by Jin et al. (1994). An explanation might lie in the chemical composition of the feed offered to the pigs. At higher maize cob inclusion levels, where energy would be low, the pigs would not obtain enough energy for protein accretion (Pond et al., 1988; Jørgensen et al., 1996). 
Weights of the intestines, therefore, are maintained or to some extent decreased, depending on the amount of energy the pigs are able to utilise from the fibrous feed (Quiniou \& Noblet, 1995; Van Milgen et al., 2001). The observed increase in length of large intestines with inclusion level of maize cob might be attributed to the prolonged presence of fibre in the gut.

$\mathrm{VH}$ and AVSA were positively correlated. The observation that VH and AVSA increase along the gut agrees with a previous study by Jin et al. (1994). A possible explanation for the reduced VH and AVSA in the duodenum segment of the small intestines might be the abrasive effects of fibrous diets offered to the pigs on the most apical part of the villi (Agyekum et al., 2012). The abrasive effects of these fibrous diets, however, were not measured in the study and therefore warrant further investigation.

An increase in VH and AVSA is regarded as an adaptive mechanism to improve the absorption of nutrients from the gut (Caspary, 1992; Langhout, 1998; Yasar \& Forbes, 1999). In growing pigs, the inclusion of $10 \%$ wheat straw has been found to increase $\mathrm{VH}$ and deeper crypts in the jejunum and ileum, and increased cell division and CD in the large intestine (Jin et al., 1994). In the current study, VH and AVSA increased with inclusion level of fibre in the diets. High fibrous diets have reduced density of nutrients. Hence, VH and AVSA increase absorptive functions to capture as many nutrients as possible for nutritional requirements to be met. The crypt region in the intestines is a site of cell regeneration. A plethora of studies have reported increased depth of crypt to in response to degeneration of cells of the villi.

The current study showed that diet quality influences villi morphology. BD of a feed can be described in terms of particle size of feed ingredients. If a feed has high bulk density, it means it has finely ground feed particles compared with a diet with low bulk density. Conversely, a diet low in bulk density has coarse feed particles. Feed with larger particle size has a lower rate of passage through the gastrointestinal tract (Warner, 1981), which results in greater contact between the food and the intestinal mucosa, thereby increasing villus height (Dahlke et al., 2003). This results in greater absorption of available nutrients from the digesta. This conforms with the findings in the current study on growing pigs in which BD influenced $\mathrm{VH}$.

NGF consists of hemi-cellulose, cellulose and lignin, and is regarded as a complete description of fibre in a diet. An earlier report (Bindelle et al., 2005) showed that increasing the level of NDF in the diet generally decreases the digestibility of nutrients. This might account for increased VH and AVSA as NDF increased. NDF might have triggered a natural increase in absorption and utilisation of nutrients by increasing $\mathrm{VH}$ and AVSA as nutrients became more limiting.

\section{Conclusion}

High levels of fibre in diets are associated with an increase in VH and AVSA of small intestines. BD and NDF were the best predictor variables influencing VH and AVSA in segments of the small intestines. BD and NDF had linear and quadratic relationships with VH and AVSA of growing pigs, respectively. Further studies are required to investigate the abrasive effects of fibrous diets on the gastro-intestinal tract of pigs.

\section{Acknowledgements}

Financial support for this study was obtained from the University of KwaZulu-Natal Competitive Research Grant. The authors thank IDEXX laboratory for preparation of slides for histomorphology measurements.

\section{Authors' contributions}

AGB designed the research project and wrote the manuscript (as part of his PhD programme). Critical revisions of the manuscript were performed by MC.

\section{Conflict of interest}

None of the authors of this work has a financial or other relationship with people or organisations that could influence inappropriately or bias the contents of this paper.

\section{References}

Agyekum, A.K., Slominski, B.A. \& Nyachoti, C.M., 2012. Organ weight, intestinal morphology, and fasting whole-body oxygen consumption in growing pigs fed diets containing distillers dried grains with solubles alone or in combination with a multi-enzyme supplement. J. Anim. Sci. 90, 3032-3040.

AOAC, 2005. Official Methods of Analysis, 18th ed. Assoc. Off. Anal. Chem, Washington, DC, USA.

Bailey, S.A., Zidell, R. H. \& Perry, R.W., 2004. Relationships between organ weight and body/brain weight in the rat: What is the best analytical endpoint? Toxicol. Pathol. 32, 448-466.

Bakare A.G., Ndou, S P., Madzimure J. \& Chimonyo M., 2016. Nutritionally related blood metabolites and performance of finishing pigs fed graded levels of fibrous diets. Trop. Anim. Health. Prod. 48(5), 1065-1069.

Bindelle, J., Sinnaeve, G., Dardenne, P., Leterme, P. \& Buldgen, A., 2005. A rapid estimation of nitrogen bound to neutral detergent fibre in forages by near infrared reflectance spectroscopy. In: O'Mara F.P. et al. Proceedings of the XXth International Grassland Congress. 26 June--1 July 2005. Dublin: University College Dublin, 259. 
Božović, I., Radosavljević, M., Žilić, S. \& Jovanović, R., 2004. A genetic base of utilization of maize cob as a valuable naturally renewable raw material. Genetika, 36, 245-256.

Caspary, W.F., 1992. Physiology and pathophysiology of intestinal absorption. Am. J. Clin. Nutr. 55, 299-308.

Dahlke, F., Ribeiro, A.M.L., Kessler, A.M., Lima, A.R. \& Maiorka, A., 2003. Effects of corn particle size and physical form of the diet on the gastrointestinal structures of broiler chickens. Braz. J. Poultry Sci. 5(1), 61-67.

De Lange, C.F.M., Birkett, S.H. \& Morel, P.C.H., 2001. Protein, fat and bone tissue growth in swine. Pages 65-84 in Swine Nutrition. A. Lewis and L. Southern, ed. CRC Press, Boca Raton, FL.

Ferraris, R.P. and Carey, H.V., 2000. Intestinal transport during fasting and malnutrition. Annu. Rev. Nutr. 20, 195-219.

Ferreira, G. \& Mertens, D.R., 2007. Measuring detergent fibre and insoluble protein in corn silage using crucibles or filter bags. Anim. Feed Sci. Technol. 133, 335-340.

Iji, P.A., Saki, A. \& Tivey, D.R., 2001. Body and intestinal growth of broiler chicks on a commercial starter diet. 1. Intestinal weight and mucosal development. Br. Poult. Sci. 42, 505-513.

Jin, L., 1992. Modulation of feed intake by weanling pigs. Ph.D. Dissertation. North Dakota State University, Fargo.

Jin, L., Reynold, L.P., Redmer, D.A., Caton, J.S. \& Crenshaw, J.D., 1994. Effects of dietary fibre on intestinal growth, cell proliferation, and morphology in growing pigs. J. Anim. Sci. 72, 2270-2278.

Jørgensen, H., Zhao X. Q. \& Bach-Knudsen, K. E., 1996. The influence of dietary fibre and environmental temperature on the development of the gastrointestinal tract, digestibility, degree of fermentation in the hind-gut and energy metabolism in pigs. Br. J. Nutr. 75, 365-378.

Langhout, D.J., 1998. The role of the intestinal flora as affected by non-starch polysaccharides in broiler chicks. PhD Thesis, Wageningen Agricultural University.

Le Goff, G., Van Milgen, J.\& Noblet, J., 2002. Influence of dietary fibre on digestive utilization and rate of passage in growing pigs, finishing pigs and adult sows. Anim. Sci. 74, 503-515.

Ma, Y., Li, D., Qiao, S.Y., Huang, C.H. \& Han, I.K., 2002. The effects of fibre source on organ weight, digesta pH, specific activities of digestive enzymes and bacterial activity in the gastrointestinal tract of piglets. Asian Australas. J. Anim. Sci. 10, 1432-1488.

Montagne, L., Pluske, J.R. \& Hampson, D.J., 2003. A review of interactions between dietary fibre and the intestinal mucosa, and their consequences on digestive health in young non-ruminant animals. Anim. Feed Sci. Technol. $108,95-117$.

Nabuurrs, M.J.A., Hoogendoorn, A., Van der Molden, E.J. \& Van Osta, A.L.M., 1993. Villous height and crypt depth in weaned and unweaned pigs, reared under various circumstances in the Netherlands. Res. Vet. Sci. 55, 78-84.

Ndou, S.P., Gous, R.M. \& Chimonyo, M., 2013. Prediction of scaled feed intake in weaner pigs using physicochemical properties of fibrous diets. Br. J. Nutr. 110, 774-780.

Ngoc, T.T.B., Hong, T.T.T., Len, N.T. \& Lindberg, J.E., 2012. Effect of fibre level and fibre source on gut morphology and micro-environment in local (Mong Cai) and exotic (Landrace x Yorkshire) pigs. Asian Australas. J. Anim. Sci. 25, 1726-1733.

Noblet, J. \& Perez, J.M., 1993. Prediction of digestibility of nutrients and energy values of pig diets from chemical analysis. J. Anim. Sci. 71, 3389-3398.

Nyachoti, C.M., De Lange, C.F.M., McBride, B.W., Leeson, S. \& Schulze, H., 2000. Dietary influence on organ size and in vitro oxygen consumption by visceral organs of growing pigs. Livest. Prod. Sci. 65, 229-237.

Peterson, D.A. \& Baumgardt, B.R., 1971. Food and energy intake of rats fed diets varying in energy concentration and density. J. Nutr. 101, 1057-1068.

Pond, W.G., Jung, H.G. \& Varel, V.H., 1988. Effects of dietary fibre on young adult genetically lean, obese and contemporary pigs: Body weight, carcass measurements, organ weights and digesta content. J. Anim. Sci. 66, 699-706.

Quiniou, N. \& Noblet, J., 1995. Prediction of tissular body composition from protein and lipid deposition in growing pigs. J. Anim. Sci. 73, 1567-1575.

Robertson, J.A. \& Eastwood, M.A., 1981. A method to measure the water-holding properties of dietary fibre using suction pressure. Br. J. Nutr., 46, 241.

Statistical Analysis Systems (SAS). 2008. SAS/STAT User's guide, Release 9.1.3. SAS Institute Inc, Cary, North Carolina, USA.

Van Milgen, J., Noblet, J., \& Dubois, S., 2001. Energetic efficiency of starch, protein and lipid utilization in growing pigs. J. Nutr. 131, 1309-1318.

Velayudhan, B.T., Daniels, K.M., Horrell, D.P., Hill, S.R., McGilliard, M.L., Corl, B. A., Jiang, H. \& Akers, R.M., 2008. Developmental histology, segmental expression, and nutritional regulation of somatotropic axis genes in small intestine of pre-weaned dairy heifers. J. Dairy Sci. 91(9), 3343-3352.

Vente Spreeuwenberg, M.A.M. \& Beynen, A.C., 2003. Diet mediated modulation of small intestine integrity in weaned pigs. In Weaning the pig: Concepts and consequences. J.R. Pluske, J.L. Dividich \& M.W.A. Verstegen (eds). Wageningen Academic Publishers, Wageningen, Netherlands, pp. 145-198.

Warner, A.C.I., 1981. Rate of passage of digesta through the gut of mammals and birds. Nutr Abstr. Rev. 51, 789-820.

Yasar, S. \& Forbes, J.M., 1999. Performance and gastrointestinal response of broiler chicks fed on cereal gain-based foods soaked in water. Br. Poult. Sci. 40, 65-76. 